\title{
QUASI-CONVEX UNIVALENT FUNCTIONS
}

\author{
K. INAYAT NOOR and D.K. THOMAS \\ Kerman University \\ P. 0. Box 182 \\ Kerman, Iran \\ University College of Swansea \\ SWANSEA SA2 8PP, Wales
}

(Received May 9, 1979 and in Revised form in June 25, 1979)

ABSTRACT. In this paper, a new class of normalized univalent functions is introduced. The properties of this class and its relationship with some other subclasses of univalent functions are studied. The functions in this class are closeto-convex.

1980 MATHEMATICS SUBJECT CLASSIFICATION CODES: Primary 30A32; Secondary $30 A 34$ KEYWORDS AND PHRASES. Univalent functions, Quasi-convex, close-to-convex.

\section{INTRODUCTION.}

Denote by $S$ the class of functions $f$ which are regular and univalent in the unit disc $E$ and satisfy $f(0)=0$ and $f^{\prime}(0)=1$. The subclasses $s^{*}$ and $C$ of starlike and convex functions respectively are well known and have been extensively studied. $\mathrm{S}^{*}$ and $\mathrm{C}$ are connected by the basic property 


$$
f \varepsilon \quad C \text { if and only if } z f^{\prime} \varepsilon S^{*} \text {. }
$$

The subclass $\mathrm{K}$ of $\mathrm{S}$ consisting of close-to-convex function is also well known and many of the properties of $\mathrm{s}^{*}$ can be extended to the wider class $\mathrm{K}$.

The purpose of this paper is to introduce a natural analogue of the class $\mathrm{C}$ in terms of the property defined in (1.1).

\section{MAIN RESULTS.}

Def. Let $f$ be regular in $E$ with $f(0)=0$ and $f^{\prime}(0)=1$. Then $f$ is said to be quasi-convex in $E$ if there exists a convex function $g$ with $g(0)=0$, $g^{\prime}(0)=1$ such that for $z \in E$,

$$
\operatorname{Re} \frac{\left(z f^{\prime}(z)\right)^{\prime}}{g^{\prime}(z)}>0
$$

Denote the class of quasi-convex functions by $Q$.

It is clear that, when $f(z) \equiv g(z), C=Q$ so that $C \subset Q$. We show first that $Q \subset K$, so that every quasi-convex functions is univalent.

THEOREM 1. Let $f \in Q$. Then, for $z \in E$,

$$
\operatorname{Re} \frac{z f^{\prime}(z)}{g(z)}>0
$$

and so $Q \subset K \subset S$; thus, every quasi-convex function is close-to-convex and hence univalent in $E$.

PROOF: A result of Libera [4] shows that, if $s$ and $t$ are functions regular in $E$ with $s(0)=t(0)=0$ and $t \varepsilon S^{*}$, then for $z \varepsilon E$,

$$
\operatorname{Re} \frac{s^{\prime}(z)}{t^{i}(z)}>0 \rightarrow \operatorname{Re} \frac{s(z)}{t(z)}>0
$$

An immediate application of this with $s(z)=z f^{\prime}(z)$ and $t(z)=g(z)$ proves 
Theorem 1.

It follows at once from the definition that

$$
f \varepsilon Q \text { if and only if } z f^{\prime} \varepsilon K \text {. }
$$

We can thus write

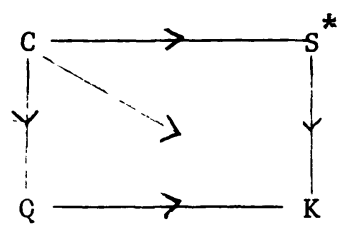

where the direction of the arrow indicates set inclusion.

Theorem 1 shows that the image domain for all $f \in Q$ is close-to-convex.

However a specific characterisation of the image domain for $f \varepsilon Q$ remains an open question.

We state now some basic properties of quasi-convex functions which can easily be extended from the class of convex functions. We omit the proofs as they are simple extensions from the convex case.

THEOREM 2. Let $f \in Q$ with $f(z)=z+\sum_{n=2}^{\infty} a_{n} z^{n}$. Then for $|z|=r<1$,

$$
\begin{aligned}
& \text { (i) }\left|a_{n}\right| \leq 1, \quad n=2,3, \ldots, \\
& \text { (ii) } \frac{1}{(1+r)^{2}} \leq\left|f^{\prime}(z)\right| \leq \frac{1}{(1-r)^{2}}, \\
& \text { (iii) } \frac{r}{1+r}-\leq|f(z)| \leq \frac{r}{1-r},
\end{aligned}
$$$$
\text { (iv) }|w| \geq \frac{1}{2} \text {, where } f(z) \neq w \text { in } E \text {. }
$$

Al1 inequalities are sharp, equality being attained for $f_{0}(z)=\frac{z}{1-z}$. 
We now give an example of a function in $Q$ which is not convex.

Example 1.3.1 Let $f_{1}$ be the Koebe function; 1.e., $f_{1}(z)=\frac{z}{(1-z)^{2}}$. Then $f_{1}$ maps E 1-1 conformally onto the w-plane cut from $-\frac{1}{4}$ to $-\infty$ along the negative real axis. Let $f_{2}: f_{2}(z)=\frac{x+z}{1+\bar{x} z}, x \in E$. Then $f_{2}$ maps $E$ onto it self and takes the origin onto the point $x$. Define $f_{3}$ by

$$
f_{3}(z)=f_{1}\left[f_{2}(z)\right]-f_{1}(x) ; f_{3}(0)=0 \text { and }
$$

$f_{3}^{\prime}(0) \neq 0$ (since $f_{3}$ is univalent), and let $f_{4}$ :

$$
f_{4}(z)=\frac{f_{3}(z)}{f_{3}^{\prime}(0)}, \quad z \in E \text {. }
$$

Combining all these transformations, we can write

$$
F(z)=\frac{f_{1}\left(\frac{x+z}{1+\overline{x z}}\right)-f_{1}(x)}{f_{1}^{\prime}(x)\left(1-|x|^{2}\right)} ; f_{1}(z)=\frac{z}{(1-z)^{2}} .
$$

The function $F$ is close-to-convex. In fact,

$$
\begin{gathered}
F^{\prime}(z)=\frac{f_{1}\left(\frac{x+z}{1+\overline{x z}}\right)}{f_{1}(x)(1+\bar{x} z)^{2}} \\
\frac{F^{\prime \prime}(z)}{F^{\prime}(z)}=\frac{f_{1}^{\prime \prime}\left(\frac{x+z}{1+\bar{x} z}\right)\left(1-|x|^{2}\right)}{f_{1}^{\prime}\left(\frac{x+z}{1+\bar{x} z}\right)(1+\bar{x} z)^{2}}-\frac{\overline{2 x}}{(1+\bar{x} z)}
\end{gathered}
$$

and 


$$
\begin{aligned}
& 1+\frac{z F^{\prime \prime}(z)}{F^{\prime}(z)}=\left\{1+\left(\frac{x+z}{1+\overline{x z}}\right) \frac{f_{1}^{\prime \prime}\left(\frac{x+z}{1+\bar{x} z}\right)}{f_{1}^{\prime}\left(\frac{x+z}{1+\overline{x z}}\right)}\right\} \frac{z\left(1-|x|^{2}\right)}{(x+z)(1+\bar{x} z)} \\
& -\frac{2 \bar{x} z}{1+\bar{x} z}-\frac{z\left(1-|x|^{2}\right)}{(x+z)(1+\bar{x} z)}+1 \\
& =\left\{1+\frac{x+z}{1+\overline{x z}} \frac{f_{1}^{\prime \prime}\left(\frac{x+z}{1+\bar{x} z}\right)}{f_{1}^{\prime}\left(\frac{x+z}{1+\bar{x} z}\right)}\right\} \frac{z\left(1-|x|^{2}\right)}{(x+z)(1+\bar{x} z)}+\frac{x-\overline{x z}{ }^{2}}{(x+z)(1+\bar{x} z)} \\
& =\left\{1+\frac{\xi f_{1}^{\prime \prime}(\xi)}{f_{1}^{\prime}(\xi)}\right\} \frac{\left(1-|x|^{2}\right) z}{(x+z)(1+\bar{x} z)}+\frac{x-\bar{x} z{ }^{2}}{(x+z)(1+\bar{x} z)}, \quad \xi=\frac{x+z}{1+\bar{x} z} \\
& \text { Let } z=r e^{i \theta}, \frac{x+r e^{i \theta}}{1+\bar{x} r e^{1 \theta}}=r_{1} e^{i p} ; \frac{r e^{i \theta}\left(1-|x|^{2}\right)}{\left(x+r e^{i \theta}\right)\left(1+\bar{x} r e^{i \theta}\right)} d \theta=d \Phi \text {. }
\end{aligned}
$$

For $\varphi_{1}$ and $\varphi_{2}$ with $\left(\varphi_{1}<\varphi_{2}\right)$, we have correspanding $\theta_{1}$ and $\theta_{2}$ with $\left(\theta_{1}<\theta_{2}\right)$. Now,

$$
\begin{aligned}
\operatorname{Re}\left\{1+r e^{i \theta} \frac{F^{\prime \prime}\left(r e^{i \theta}\right)}{F^{\prime}\left(r e^{i \theta}\right)}\right\} d \theta & =\operatorname{Re}\left\{1+\frac{\xi_{1}^{\prime \prime}(\xi)}{f_{1}^{\prime(\xi)}}\right\} d \phi ; \quad \xi=r_{1} e^{i \varphi} \\
& =\operatorname{Re}\left\{1+r_{1} e^{i \varphi} \frac{f_{1}^{\prime \prime}\left(r_{1} e^{i \varphi}\right)}{f_{1}^{\prime}\left(r_{1} e^{i \phi}\right)}\right\} d \varphi .
\end{aligned}
$$


Hence, for $\phi_{1}<\phi_{2}$ and $\theta_{1}<\theta_{2}$,

$$
\int_{\theta_{1}}^{\theta_{2}} \operatorname{Re}\left\{1+r e^{i \theta} \frac{F^{\prime \prime}\left(r e^{i \theta}\right)}{F^{\prime}\left(r e^{i \theta}\right)}\right\} d \theta=\int_{\phi_{1}}^{\phi_{2}} \operatorname{Re}\left\{1+r_{1} e^{i \phi} \frac{f_{1}^{\prime \prime}\left(r_{1} e^{i \phi}\right)}{f_{1}^{\prime}\left(r_{1} e^{i \phi}\right)}\right\} d \Phi>-\pi,
$$

which shows that $\mathrm{f} \varepsilon \mathrm{K}$.

Now,

$$
\begin{aligned}
F^{\prime}(z) & =\frac{\left(1+\frac{x+z}{1+\bar{x} z}\right)}{\left(1-\frac{x+z}{1+\bar{x} z}\right)^{3}} \cdot \frac{(1-x)^{3}}{(1+x)} \cdot \frac{1}{(1+\bar{x} z)^{2}} \\
& =\frac{\left.1+\frac{\overline{1+x}}{1+x}\right)}{\left(1-\frac{\overline{1-x}}{1-x}\right)^{3}} \\
& =\frac{(1+\beta z)}{(1-\alpha z)^{3}} ; \quad \beta=\frac{\overline{1+x}}{1+x}, \quad \alpha=\frac{1-x}{1-x} ; \quad|\alpha|=1=|\beta| .
\end{aligned}
$$

Intergrating, we have for $\mathrm{z} \varepsilon \mathrm{E}$,

$$
F(z)=\frac{z\left(1+\frac{\beta-\alpha}{2} z\right)}{(1-\alpha z)^{2}} .
$$

We notice that $\mathrm{F}$ maps $\mathrm{E}$ onto the w-plane cut along a half-line $\ell$. Since the choice of the point $x$ in $E$ is arbitrary, we can select $x$ in such a way that the half-line $\mathcal{E}$ does not pass through the origin in $F(E)$, which means $F$ is not, in general, starlike. Because of relationships (3) and (1) between the classes $Q$ and $K-\Omega$ and $S^{*}$, we conclude that, in general, 
the function $f_{*}$ defined in $E$ by $f_{\star}(z)=\int_{0}^{2} \frac{F(\xi)}{\xi} d \xi$ belongs to $Q$ but not to C.

3. SOME GROWTH PROBLEMS

Clunie and Keogh [1] showed that, if $f \varepsilon C$ with $f(z)=z+\sum_{n=2}^{\infty} a_{n} z^{n}$ and $f(E)$ has finite area. Then $n a_{n}=o(1)$ as $n \rightarrow \infty$ and the exponent is best possible. We extend this result to quasi-convex functions.

THEOREM 3. Let $f \varepsilon Q$ with $f(z)=z+\sum_{n=2}^{\infty} a_{n} z^{n}$. If $f(E)$ has finite area, then $\mathrm{n} \mathrm{a}_{\mathrm{n}}=\mathrm{o}(1)$ as $\mathrm{n} \rightarrow \infty$, the index of $\mathrm{n}$ being best possible.

PROOF: We use a modified version of the method of clunie and Pommerenke [2].

By (2), we can write

$$
\left(z f^{\prime}(z)\right)^{\prime}=g^{\prime}(z) h(z),
$$

where $\operatorname{Re} h(z)>0$ for $z \varepsilon E$ and $h(0)=1$. Thus,

$$
z\left(z f^{\prime}(z)\right)^{\prime}=2 z g^{\prime}(z) \operatorname{Reh}(z)-z g^{\prime}(z) \overline{h(z)} \text {, }
$$

and so with $z=r e^{i \theta}, 0 \leq r<1$, Cauchy's formula gives for $n \geq 1$

$$
\begin{aligned}
n^{2} a_{n} & =\frac{1}{2 \pi r^{n}} \int_{0}^{2 \pi} z\left(z f^{\prime}(z)\right)^{\prime} e^{-i n \theta} d \theta \\
& =\frac{1}{\pi r^{n}} \int_{0}^{2 \pi} z g^{\prime}(z) \operatorname{Re} h(z) e^{-i n \theta} d \theta-\frac{1}{2 \pi r^{n}} \int_{0}^{2 \pi} z g^{\prime}(z) \overline{h(z)} e^{-i n \theta} d \theta .
\end{aligned}
$$

Since $\operatorname{Re} h(z)>0$ for a $\varepsilon E$,

$$
n^{2}\left|a_{n}\right| \leq \frac{1}{\pi r^{n}} \int_{0}^{2 \pi}\left|z g^{\prime}(z)\right| \operatorname{Re} h(z) d \theta+\frac{1}{2 \pi r^{n}}\left|\int_{0}^{2 \pi} z g^{\prime}(z) h(z) e^{i n \theta} d \theta\right| \text {. }
$$


Now $\left|z g^{\prime}(z)\right| \operatorname{Re} h(z)=\operatorname{Re}\left[\left|z g^{\prime}(z)\right| h(z)\right]$

$$
=\operatorname{Re}\left[z\left(z f^{\prime}(z)\right)^{\prime} e^{-\operatorname{Iarg} z g^{\prime}(z)}\right] \text { from (3.1), and so inte- }
$$

grating the first of the above two integrals by parts we have

$$
\begin{gathered}
\frac{1}{\pi r^{n}} \int_{0}^{2 \pi}\left|z g^{\prime}(z)\right| \operatorname{Re} h(z) d \theta=\operatorname{Re} \frac{1}{\pi r^{n}}\left[\int_{0}^{2 \pi} z\left(z f^{\prime}(z)\right) e^{-\operatorname{targ} z g^{\prime}(z)} d \theta\right] \\
=\operatorname{Re} \frac{1}{\pi r^{n}} \int_{0}^{2 \pi} z f^{\prime}(z) e^{-i \arg z g^{\prime}(z)} d_{\theta}\left(\arg z g^{\prime}(z)\right)
\end{gathered}
$$

Also, $\overline{z g^{\prime}(z)} h(z)=z\left(z f^{\prime}(z)\right)^{\prime} e^{-2 i \arg z g^{\prime}(z)}$ and so (3.2) and (3.3) give

$$
\begin{aligned}
& n^{2}\left|a_{n}\right| \leq \frac{1}{\pi r^{n}} \int_{0}^{2 \pi} \operatorname{Re}\left[z f^{\prime}(z) e^{-i \arg \pi g^{\prime}(z)}\right] d_{\theta}\left(\arg z g^{\prime}(z)\right) \\
&+\frac{1}{2 \pi r^{2 n}}\left|\int_{0}^{2 \pi} z^{n+1}\left(z f^{\prime}(z)\right)^{\prime} e^{-2 i \arg z g^{\prime}(z)} d \theta\right| \\
&= \frac{1}{\pi r^{n}} I_{1}+\frac{1}{2 \pi r^{2 n}} \cdot I_{2} \text {, say. }
\end{aligned}
$$

To estimate $I_{1}$, we note that, since $f$ is regular in $E$ and the area of $f(E)$ is finite, $M\left(r, f^{\prime}\right)=\frac{o(1)}{1-r}$ as $r+1$. where $M(r, f)=\max _{\theta}\left|f\left(r e^{i \theta}\right)\right|$. Since $\int_{0}^{2 \pi} d_{\theta}\left(\arg z g^{\prime}(z)\right)=2 \pi$, we have $I_{1}=\frac{Q(1)}{1-r}$ as $r \rightarrow 1$. 
Integrating $I_{2}$ by parts gives

$$
I_{2}=2\left|\int_{0}^{2 \pi} F_{n}(z) e^{-2 i \arg z g^{\prime}(z)} \operatorname{Re} \frac{\left(z g^{\prime}(z)\right)^{\prime}}{g^{\prime}(z)} d \theta\right|,
$$

where

$$
F_{n}(z)=\int_{0}^{z} t^{n}\left(t f^{\prime}(t)\right)^{\prime} d t=z^{n+1} f^{\prime}(z)-n f_{n}(z),
$$

and

$$
f_{n}(z)=\int_{0}^{z} t^{n} f^{\prime}(t) d t .
$$

Now

$$
\begin{aligned}
\left|F_{n}(z)\right| & \leq r^{n+1} M\left(r, f^{\prime}\right)+n M\left(x, f^{\prime}\right) \int_{0}^{r} t^{n} d t \\
& \leq 2 r^{n+1} M\left(r, f^{\prime}\right) .
\end{aligned}
$$

Since $\int_{0}^{2 \pi} \operatorname{Re} \frac{\left(z g^{\prime}(z)\right)^{\prime}}{g^{\prime}(z)} d \theta=2 \pi$, we have

$$
I_{2} \leq 8 \pi r^{n+1} M\left(r, f^{\prime}\right)=\frac{o(1)}{1-r} \text { as } r \rightarrow 1 \text { as before. }
$$

Finally, choosing $r=1-\frac{1}{n}$ in (3.4), the estimates for $I_{1}$ and $I_{2}$ give $\mathrm{na}_{\mathrm{n}}=\mathrm{o}(1)$ as $\mathrm{n} \rightarrow \infty$, and Theorem 3 is proved.

An examination of the proof of Theorem 3 gives COROLLARY: Let $\mathrm{f} \varepsilon Q, \mathrm{E}_{\mathrm{r}}=\{\mathrm{z}:|z|=r<1\}$ and $A(r)$ be the area of $f\left(E_{r}\right)$. Then, for $\mathrm{n} \geq 2$, 


$$
\mathrm{n}\left|\mathrm{a}_{\mathrm{n}}\right|=0(1) \mathrm{A}\left(1-\frac{1}{\mathrm{n}}\right)^{\frac{1}{2}}
$$

We remark that (3.5) holds for the class $\mathrm{s}^{*}$, but appears still to be an open problem for the class $\mathrm{x}$.

Denote by $C(r)$ the closed curve which is the image of $f\left(E_{r}\right)$ and by $L(r)$ the length of $\mathrm{C}(\mathrm{r})$. We prove

THEOREM 4. Let $\mathrm{f} \varepsilon \mathrm{Q}$. Then, for $0 \leq \mathrm{r} \leqslant 1$,

$$
2 \sqrt{ }(\pi \mathrm{A}(\mathrm{r})) \leq \mathrm{L}(\mathrm{r}) \leq 2 \sqrt{ }(\pi \mathrm{A}(\sqrt{ } \mathrm{r}))\left(\log \frac{1}{1-\mathrm{r}}\right)^{\frac{1}{2}} .
$$

Further, if $A(r)<\infty$ for $0 \leq r<1$, then

$$
L(r)=o(1)\left(\log \frac{1}{1-r}\right)^{\frac{1}{2}} \text { as } r+1
$$

PROOF: The left hand inequality follows at once. from the isoperimetric inequality. Since $f \varepsilon Q, F(z)=z f^{\prime}(z)$ is close-to-convex. Thus from [3,p.45]

$$
\begin{aligned}
L(r) & =\int_{0}^{2 \pi}\left|z f^{\prime}(z)\right| d \theta=\int_{0}^{2 \pi}|B(z)| d \theta \\
& \leq 2 \pi \int_{0}^{r} M\left(\rho, z f^{\prime}\right) \frac{d \rho}{\rho} \\
& \leq 2 \pi \sum_{n=1}^{\infty}\left|a_{n}\right| r^{n} \\
& \leq 2 \pi\left(\sum_{n=1}^{\infty} n\left|a_{n}\right|^{2} r^{n}\right)^{\frac{1}{2}}\left(\sum_{n=1}^{\infty} \frac{r^{n}}{n}\right)^{\frac{1}{2}} \\
& =2 \sqrt{\frac{1}{2}}(\pi A(\sqrt{r})) \log _{1-r}^{1}
\end{aligned}
$$


If $a(r)<\infty$ for $0 \leq r<1$, then from (3.7)

$$
\begin{aligned}
L(r) & =2 \pi \sum_{n=1}^{\infty}\left|a_{n}\right| r^{n} \\
& \leq 2 \pi \sum_{n=1}^{N}\left|a_{n}\right| r^{n}+\sum_{n=N}^{\infty} n\left|a_{n}\right|^{2} \frac{1}{2} \sum_{n=1}^{\infty} \frac{r^{2 n}}{n}{ }^{\frac{1}{2}} \\
& =2 \pi \sum_{n=1}^{N}\left|a_{n}\right| r^{n}+\delta_{N} \log _{1-r^{2}}^{1 / 2}
\end{aligned}
$$

where $\delta_{N} \rightarrow 0$ as $\mathrm{N} \rightarrow \infty$. Thus $\mathrm{L}(\mathrm{r})=0(1) \quad \log _{\frac{1}{1-\mathrm{r}}}^{\frac{1}{2}}$ as $\mathrm{r} \rightarrow 1$.

The convex function $f_{1}(z)=\log \frac{1}{1-z}$ shows that the factor $\log _{1-r} \frac{1 / 2}{\text { in }}$ (3.6) is best possible.

For $f \varepsilon C$ it is well know that $L(r) \leq 2 \pi M(r)$. It follows from (3.6) that for $f \in Q, L(r)=0(1) M(r) \log \frac{1}{1-r}$ as $r \rightarrow 1$. The question of whether the factor $\log _{1-r}$ can be removed remains open.

In conclusion, we remark that other results for the class $C$ can be extended to quasi-convex functions, often with only minor alterations in the proof. The objective of this paper has been to introduce the class $Q$, exhibit its basic properties and give some results whose proofs are not trivial extenstons from the class $\mathrm{C}$. 


\section{REFERENCES}

1. CLUNIE,J.G. and KEOGH, F.R., "On starlike and convex schlicht functions", J. London Math.Soc., 35 (1960), 229-233.

2. CLUNIE, J.G. and POMMERENKE, Ch., "On the coefficients of close-to-convex univalent functions", J. London Math.Soc., 41 (1966), 161-165.

3. HAYMAN, W.K., 'Multivalent functions', Cambridge, 1967.

4. LIBERA, R.J., "Some classes of regular univalent functions", Proc.Amer. Math Soc., 16 (1965), 755-758. 


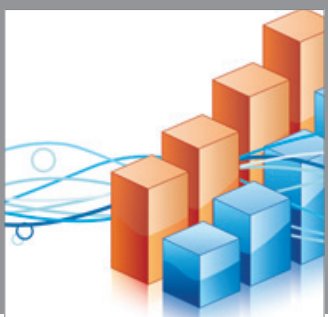

Advances in

Operations Research

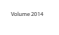

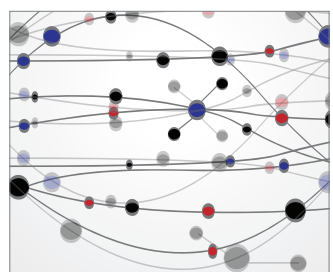

\section{The Scientific} World Journal
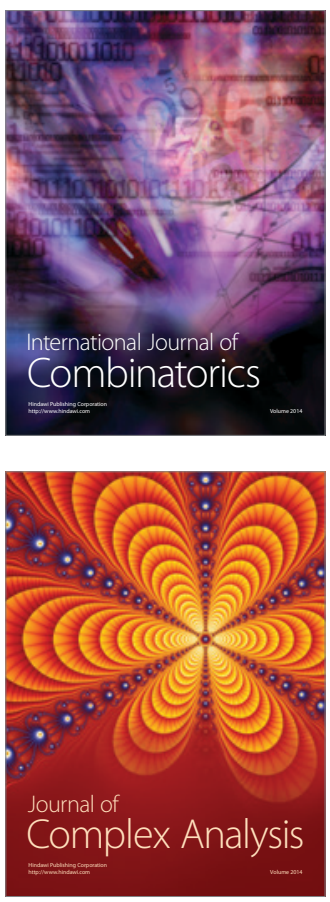

International Journal of

Mathematics and

Mathematical

Sciences
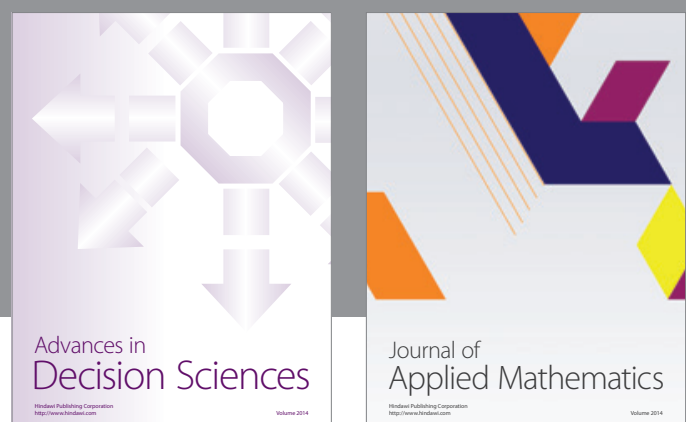

Journal of

Applied Mathematics
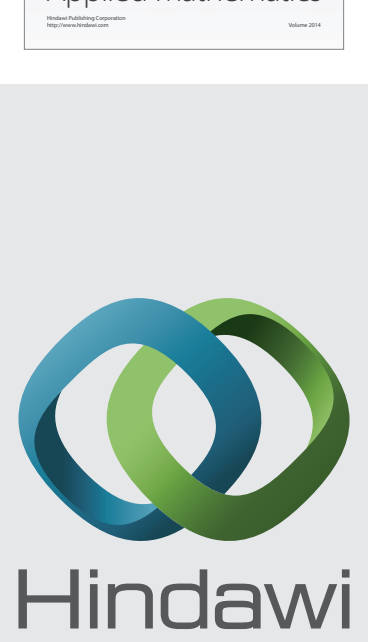

Submit your manuscripts at http://www.hindawi.com
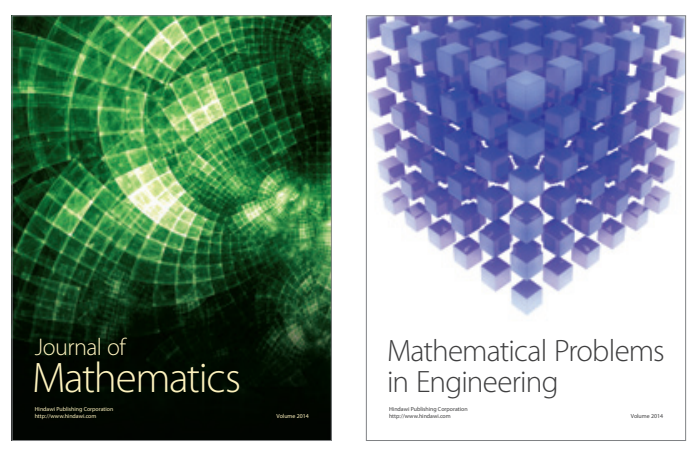

Mathematical Problems in Engineering
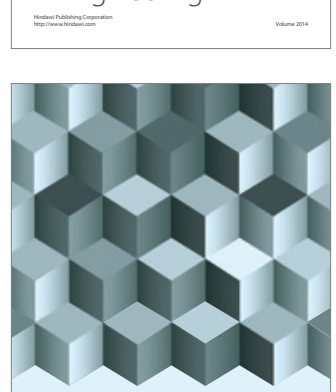

Journal of

Function Spaces
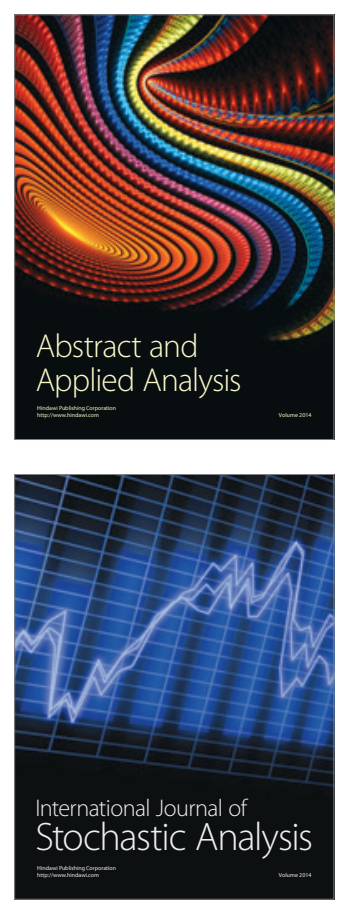

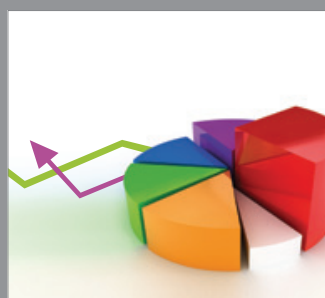

ournal of

Probability and Statistics

Promensencen
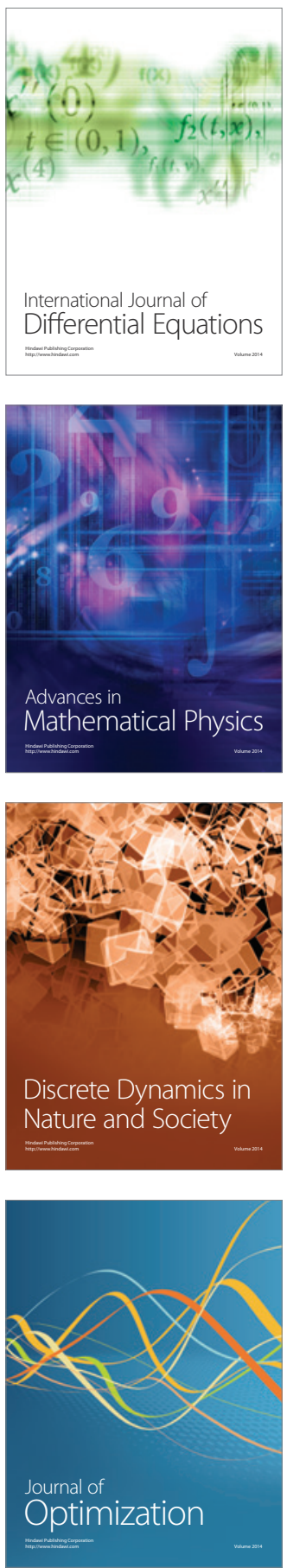